\title{
Is Embodied Cognition Bilingual? Current Evidence and Perspectives of the Embodied Cognition Approach to Bilingual Language Processing
}

\author{
Katharina Kühne and Claudia Gianelli* \\ Division of Cognitive Sciences, University of Potsdam, Potsdam, Germany
}

Accumulating behavioral and neurophysiological evidence supports the idea of language being grounded in sensorimotor processes, with indications of a functional role of motor, sensory and emotional systems in processing both concrete and abstract linguistic concepts. However, most of the available studies focused on native language speakers $(\mathrm{L} 1)$, with only a limited number of investigations testing embodied language processing in the case of a second language (L2). In this paper we review the available evidence on embodied effects in L2 and discuss their possible integration into existing models of linguistic processing in L1 and L2. Finally, we discuss possible avenues for future research towards an integrated model of $\mathrm{L} 1$ and $\mathrm{L} 2$ sensorimotor and emotional grounding.

Keywords: embodied language, grounding, sensorimotor, native language, second language

Reviewed by:

Max Garagnani,

Goldsmiths University of London,

United Kingdom

John Stins,

VU University Amsterdam,

Netherlands

*Correspondence:

Claudia Gianelli

claudia.gianelli@uni-potsdam.de;

isotopia@gmail.com

Specialty section:

This article was submitted to

Cognition,

a section of the journal

Frontiers in Psychology

Received: 27 November 2017

Accepted: 14 January 2019

Published: 06 February 2019

Citation:

Kühne K and Gianelli C (2019) Is

Embodied Cognition Bilingual?

Current Evidence and Perspectives

of the Embodied Cognition Approach

to Bilingual Language Processing.

Front. Psychol. 10:108.

doi: 10.3389/fpsyg.2019.00108

\section{INTRODUCTION}

Amodal system theories of language suggest that cognition is built of abstract amodal representations via formal rules, related to their referents (Newell and Simon, 1972; Collins and Loftus, 1975). These theories presuppose that lower-level processes of perception and action play no role in forming cognition (Ojemann, 1991). This assumption has recently been challenged by studies demonstrating that neural sensorimotor systems are also active during language processing (Buccino et al., 2001; Hauk et al., 2004; Hauk and Pulvermüller, 2004; Shtyrov et al., 2004; Pulvermüller et al., 2005; Tettamanti et al., 2005; Sakreida et al., 2013), suggesting that language is grounded in bodily action and perception, or 'embodied'. Numerous studies have demonstrated how processing linguistic items with sensory, motor and emotional content re-activate the same neural structures as the experience of that content (e.g., executing a certain action, or feeling a certain emotion). Noteworthy, while most research has so far focused on how concrete concepts are grounded in sensorimotor processes, there is evidence suggesting that also more abstract concepts might be similarly grounded (for review see Fischer and Zwaan, 2008; Pulvermüller and Fadiga, 2010; Buccino et al., 2016).

Despite the accumulating evidence, however, the exact functional role of these activations remains debated. One possibility is that embodied mechanisms are indeed an inseparable and functionally crucial part of language processing (Vukovic et al., 2017). Oppositely, they might represent just a by-product of language processing (e.g., as a post-lexical simulation), functionally "redundant" and irrelevant to the efficient semantic comprehension (Mahon and Caramazza, 2008; Lotto et al., 2009). Crucial in this sense is to demonstrate whether embodied processes are automatic and universal mechanisms of linguistic processing, or they are shaped by our sensory, motor, emotional, and linguistic experience. 


\section{L1 AND L2 GROUNDING IN BODILY AND LINGUISTIC EXPERIENCE}

Fundamental to the hypothesis of language grounding in sensorimotor processes, is the assumption that linguistic and sensorimotor experience develops with similar timings in early developmental stages. While this is mostly the case for a first language (L1), typically it is not for second language (L2) late learners who do not grow up as bilinguals (MacWhinney, 2005). Pulvermüller (1999) showed that during first language acquisition a strong bond between context, sensory-motor experience and language is established. During the so-called "babbling phase" (6-12 months old) perceptual sensitivities of a child "learn" to reflect the tuning of the native language (Werker and Tees, 1999; Pulvermüller and Fadiga, 2010).

Subsequently, word learning is often accompanied by a direct association to objects, actions and properties of their referents in the environment (Carey and Bartlett, 1978; Bloom, 2000; Zwaan and Madden, 2005). These sensory and motor experiences become reactivated when the child and later the adult, encounters the word. In addition, in daily life action verbs often co-occur with bodily movements or visual sensations, contributing to strengthening the link between sensorimotor programs and linguistic concepts (Vukovic and Shtyrov, 2014). Moreover, children also learn the syntactical construction allowing transferring concrete experiences to an abstract meaning, such as in "tell them a story". This would be associated with a speech motor program and support embodiment effects when processing metaphors and abstract language (Zwaan and Madden, 2005).

Thus, while L1 is acquired in a strong connection to bodily sensations and motor programs and is used daily, L2 is usually learned through symbol manipulation, often based on L1 through analogy or translation and is used in specific settings (school, work, and reading). However, new concepts might borrow sensorimotor groundings from previously grounded symbols (Symbol Grounding Theory, Harnad, 1990). In this view, L2 concepts would acquire their sensorimotor grounding from the equivalent L1 concepts. If so, typical paradigms of embodied cognition tested in L2 speakers would be expected to produce similar effects, although possibly with differences in magnitude and/or the time-course.

\section{TESTING THE LANGUAGE GROUNDING HYPOTHESIS IN L2}

Evidence directly addressing the hypothesis of language grounding from an embodied cognition point of view is still limited. The studies discussed in this section are summarized in Table 1.

At the behavioral level, a few studies seem to support the idea that during L1 and L2 processing of action-related verbs and nouns, sensorimotor information is similarly activated, though probably only partially (Foroni, 2015). Using a Stroop paradigm, Dudschig et al. (2014) found that L2 automatically triggers action-sentence compatibility effects both for implicit location words (e.g., roof) and emotion words (e.g., happy) in an adapted version of the classic paradigm (ACE; Glenberg and Kaschak, 2002). This paradigm typically employs sentences implying a movement either away from the body or toward the body, such as "You gave the pizza to Andy", or "Andy gave the pizza to you.". Participant judge the sensibility of this sentences responding with a movement away/towards the body. In this design, reading times are typically faster in presence of a match between response movements and direction implied by the linguistic stimuli (Lachmair et al., 2011). Since the ACE effect presupposes contextual coupling of language and sensorimotor processing, the results by Dudschig and colleagues provides additional evidence for reactivation of experiential traces of these associations (Glenberg and Kaschak, 2002).

Buccino et al. (2017) recently replicated in L2 the typical motor system modulation induced in L1 by nouns referring to graspable objects as compared to non-graspable ones (Marino et al., 2014). In a go-no go paradigm, motor responses of Italian participants with very good English proficiency showed a significant modulation similar to previous results in L1.

At the neural level, Parker Jones et al. (2012) studied brain activations in native and non-native English speakers with high English proficiency while reading words out loud and during a word-picture matching task. Stimuli included written object names, familiar objects, pictures and symbols. Their study demonstrated that, in comparison to native speakers, non-native English speakers had higher levels of activation in temporal and frontal areas, supposedly because foreign language might need more effort while being retrieved and articulated (McDonald, 2006). Similar results in language as well as in motor-related brain regions for L2 speakers were also reported by Rüschemeyer et al. (2006). Their fMRI experiment based on a violation paradigm conveyed an increased activation of left inferior frontal gyrus as a reaction to a semantic violation in both L1 and L2 speakers, consistently in both auditory and written stimuli. Thus, both L1 and L2 speakers engaged the same cortical network to process language, but with higher activations for L2 speakers.

In the same vein, De Grauwe and colleagues used a lexical decision task showing in fMRI that L2, as well as L1, semantic representations can produce activations to simple motor verbs in motor and somatosensory regions (De Grauwe et al., 2014). Thus, embodiment effects with simple verbs were present with both L1 and L2.

One might argue, though, following Vukovic and Shtyrov (2014), that fRMI does not possess enough temporal resolution to investigate the time-course of linguistic processes and might only show secondary post-comprehension processes (Toni et al., 2008). In the specific case of comparison of L1 and L2 processing, it might thus hinder differences in temporal dynamics of the two processes.

Data collected using M/EEG or focal Transcranial Magnetic Stimulation (TMS) might overcome this limitation but the available evidence is still insufficient. Vukovic and Shtyrov (2014) presented a crucial quantitative difference between L1 and L2 in an equally rapid (from $150 \mathrm{~ms}$ on in both languages) motorcortex involvement. The reported effect, in fact, was stronger 


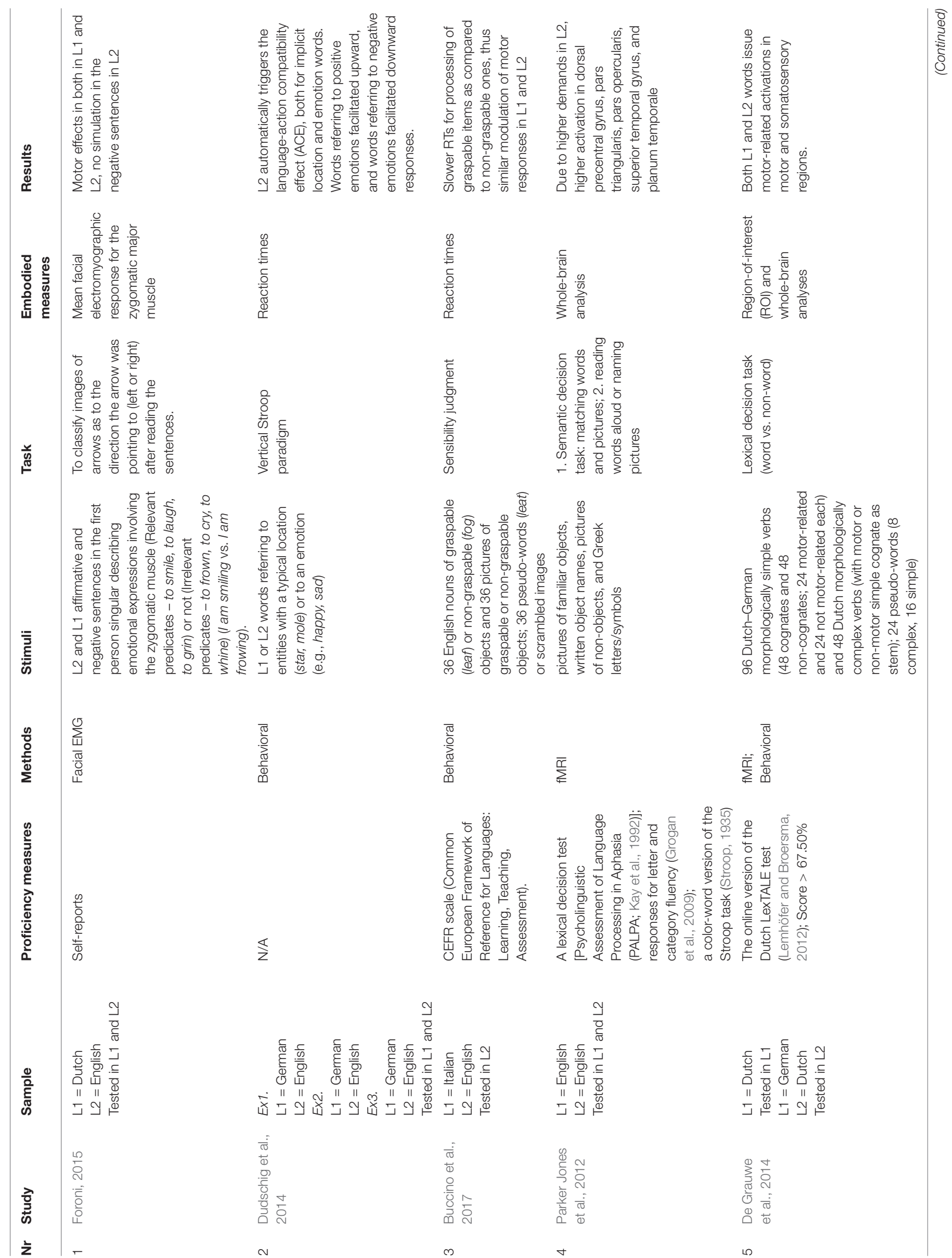







for native speakers. Recent TMS results from our laboratory, showed the same modulation of cortical excitability following presentation of pairs of action words in both L1 and L2 (Gianelli et al., 2018, preprint). Notably, the direction and timing of this modulation was comparable to the one induced by visual action processing, pointing to a shared system of action semantics.

\section{GROUNDING OF ABSTRACT CONCEPTS IN L1 AND L2}

Evidence on L2 grounding effects induced by abstract words is particularly scarce, possibly as a result of the available contradicting evidence of embodiment in L1 for abstract linguistic concepts (Borghi et al., 2017). A large amount of abstract vocabulary has been believed to carry a large emotional load, and several studies have shown that embodiment is also possible through emotion, not only through motion (Moseley and Pulvermüller, 2014; Baumeister et al., 2015; Moseley and Pulvermüller, 2018; see Pulvermüller, 2013 and Moseley et al., 2015 for review). Interestingly, in contrast to the belief that abstract words in both languages are learned relatively later than concrete ones (Chomsky, 1965; Clark and Paivio, 1991), there is evidence that emotional abstract words in L1 are learned much earlier even than concrete concepts, in an immediate interchange between the babies and mother or the caregiver (Kousta et al., 2011). A recent study about abstract vocabulary development found that children mostly learn abstract concepts at the age between 6 and 10, but valenced words are learned quite early at the age of 7 or 8 (Vigliocco et al., 2017). In another study, adults were asked to evaluate the age of positive, negative and neural abstract words acquisition (Ponari et al., 2017). Notably, positive and negative (valenced) words were acquired earlier than neutral ones.

The semantic aspects of abstract words might depend much more on the context in which they were learned (Williams and Cheung, 2011). Thus, speakers of different languages might have different emotional connotations of one word (Eilola and Havelka, 2011). Several studies have revealed higher emotional involvement during L1 processing: for instance, that it is easier to swear in a non-native language (Harris et al., 2003; Dewaele, 2004). Self-rated L2 proficiency significantly predicted perception of emotional force of taboo words. Negative abstract words elicit stronger arousal in L1 compared to L2, especially when L2 was acquired in an adult age. On the other hand, evidence from an eye-tracking study by Sheikh and Titone (2016) suggests an emotional grounding only for positive words: only positive, and not negative, words were in fact read more quickly than neutral words in L2.

\section{THEORIES OF L1 AND L2 PROCESSING}

From the reviewed evidence, an explicit sensorimotor and emotional grounding approach to L2 has so far been taken only by a limited number of studies. However, it is worth noting that evidence on L1 and L2 outside this particular approach is much more extensive and has produced several competing models and hypotheses regarding the neural bases of L1 and L2. It is worth briefly reviewing them in order to discuss whether and how the embodied cognition evidence might support the existing models.

According to the so-called differential hypothesis (Ullman, 2001), different neural mechanisms support L1 and L2 processing. This hypothesis is supported by empirical evidence from experiments of selective recovery with bilingual patients (Aglioti and Fabbro, 1993; Mehrpour et al., 2014). In bilingual aphasic patients recovery of linguistic abilities first takes place in only one of the languages and later in the other one. In contrast, the neural convergence hypothesis (Green, 2003) claims that acquisition and processing of L2 is based on the same neural mechanisms as L1 (Perani and Abutalebi, 2005; Abutalebi, 2008) and only differs as to the age of acquisition, the task and the level of proficiency (Liu and Cao, 2016). The more fluency L2 speakers gain, the more similarity there is between L2 and L1. Most evidence agrees on the common neural bases of L1 and L2 processing (Perani and Abutalebi, 2005), with the latter possibly having a more complex structure of activation. For example, several studies found divergence in time-course and in activation topography between semantic and phonological tasks between L1 and L2 (Marian et al., 2003; Pillai et al., 2003). A connected issue is the question whether lexical candidates from both languages are activated and whether they are stored in one integrated lexicon or different ones (Dijkstra and Van Heuven, 2002), constituting the so-called language non-selective vs. language selective access hypotheses. The Bilingual Interactive Activation (BIA) model (Dijkstra et al., 1998) is a language comprehension model that claims that lexical access is non-selective and lexical items are stored in one unique mental lexicon. This model posits a non-selective bottom-up processing at the level of the following language nodes: features, letters, words, language. On visual input onset, features inhibit those letters for which these particular features are absent and excite those letters for which the features are present. The letters, in their turn, inhibit or excite words if they are present or absent, respectively, and words inhibit each other irrespective of the language. Finally, the corresponding language nodes are also activated. An important part of this model is a language selective top-down inhibition, meaning that language nodes send inhibitory signals to all the words in another language. L2 words also activate the L1 words that activate the L1 language node, which, in turn, inhibits L2 words. Thus, lexical candidates from both languages are activated. The more recent $\mathrm{BIA}+$ model extends these assumptions from orthographic representations to phonological and semantic representations (Dijkstra and Van Heuven, 2002). Multiple empirical findings support this hypothesis: neighborhood density effects within and between languages (Van Heuven et al., 1998; Dijkstra and Van Heuven, 2002), shifting neighborhood effects across an experiment, masked orthographic priming effects in within and between languages in bilinguals (BijeljacBabic et al., 1997), language switching effects in lexical decision task (Von Studnitz and Green, 1997). Today, most scientists agree that bilingual speakers activate both languages (Costa et al., 2017). 
Recent evidence suggests an automatic activation of the native language while processing L2: Vukovic and Williams (2014) tested Dutch participants hearing English sentences containing interlingual homophones suggesting certain distance relations and instructed them to respond to pictures matching or mismatching this distance. Their results showed that participants automatically activate $\mathrm{L} 1$ meanings when reading $\mathrm{L} 2$ homophone sentences.

According to these models, if language is indeed embodied and grounded in sensorimotor (and possibly emotional) processes, then a similar engagement of these systems should be expected regardless of the use of L1 or L2. However, the time course might differ, with later L2 effects (Hahne, 2001; Spalek et al., 2014). These effects would be compatible with the hypothesis of L 2 effects being mediated by an L1 motor resonance (Foroni, 2015).

Similar temporal dynamics, on the other hand, would support effects directly produced by L2 linguistic stimuli, not mediated by L1. This would for instance be in line with the Revised Hierarchical Model (RHM) (Kroll and Stewart, 1994; Kroll et al., 2010), a language production model in favor of the selective activation hypothesis. This model postulates that, depending on the context, bilinguals activate either the L1 or the L2 lexicon selectively. This model postulates that bilingual memory is a hierarchical system with two levels of representation: lexical store and the conceptual level. Between the lexical representations in $\mathrm{L} 1$ and $\mathrm{L} 2$ as well as between the lexical representations in each language, there is supposed to be a level of conceptual representations, the latter being shared between the languages in most cases, except for more abstract words. This model predicts the development of these links along with L2 acquisition. In the beginning phase, the connections between the lexical level in the L2 and the conceptual level are very weak and more affected by formrelated variables, and strengthen as the individual gains a higher L2 proficiency. Numerous cross-language semantic priming studies provide empirical evidence confirming the RHM (Kroll and Borning, 1987; De Groot and Nas, 1991). A critical important assumption of the RHM is that both the age of L2 acquisition and the L2 learning context - a formal or a natural setting - modulate the effects of semantics on L2 (Ferré et al., 2006). Later studies suggest that there is not only a link between the L1 and L2 semantics, but specifically to those aspects of L2 semantics, which were active during the learning phase (Williams and Cheung, 2011). In this sense evidence collected from embodied cognition paradigms, which take into account the timings and proficiency of both sensorimotor and linguistic learning, might provide crucial support for this assumption.

\section{REFERENCES}

Abutalebi, J. (2008). Neural aspects of second language representation and language control. Acta Psychol. 128, 466-478. doi: 10.1016/j.actpsy.2008. 03.014

Aglioti, S., and Fabbro, F. (1993). Paradoxical selective recovery in a bilingual aphasic following subcortical lesion. Neuroreport 4, 1359-1362. doi: 10.1097/ 00001756-199309150-00019

\section{CONCLUSION}

It is evident that approaching L1 and L2 processing from an embodied point of view is a new and complex area of research. On the one hand, L2 poses a challenge to strong views of embodied cognition: if linguistic concepts are deeply rooted in sensorimotor processes, then this should be true regardless of the use of L1 or L2. On the other hand, the same assumption of a strong link between sensorimotor experience and linguistic concepts, would predict differences between L1 and L2 grounding based on their age of acquisition.

Furthermore, when approaching L1 and L2 existing competing models should be taken into account and integrated models should be produced including evidence based on the embodied and grounding hypothesis. In this sense, these models should take into account several parameters, including localization, magnitude and timing of the embodied effects.

The use of methodologies with high temporal resolution, such as M/EEG, or allowing focal brain stimulation (TMS), will be crucial for disentangling the time course of effects in L1 and L2. In addition, behavioral measures collected in various tasks, will allow a more complete view of how L1 and L2 linguistic concepts are shared or differentially activated. The possible taskdependency of these effects- an issue already recognized in the embodied language literature - has to be even more carefully addressed when testing L2 as it might either support or conflict with existing strategies used for language acquisition and/or memory retrieval. Such an improved methodological approach would help in clarifying the different functional role of language grounding in L1 and L2.

In the same vein, researchers should focus on formalizing the way linguistic experience (e.g., age of acquisition, proficiency, L2 acquisition strategies) can be factored into the experimental design. Finally, the advancement of research on embodiment in L2 will necessary profit from the extension of the stimuli from single nouns or verbs to more complex sentences, as well as towards the use of abstract and emotional stimuli.

\section{AUTHOR CONTRIBUTIONS}

CG and KK wrote and approved the final version of this manuscript.

\section{FUNDING}

This work was funded by a DAAD-MIUR Joint Mobility grant (project no. 57266099) to CG.

Baumeister, J. C., Rumiati, R. I., and Foroni, F. (2015). When the mask falls: the role of facial motor resonance in memory for emotional language. Acta Psychol. 155, 29-36. doi: 10.1016/j.actpsy.2014.11.012

BijeljacBabic, R., Biardeau, A., and Grainger, J. (1997). Masked orthographic priming in bilingual word recognition. Mem. Cogn. 25, 447-457. doi: 10.3758/ BF03201121

Bloom, P. (2000). How Children Learn the Meanings of Words. Cambridge, MA: The MIT Press. doi: 10.7551/mitpress/3577.001.0001 
Borghi, A. M., Binkofski, F., Castelfranchi, C., Cimatti, F., Scorolli, C., and Tummolini, L. (2017). The challenge of abstract concepts. Psychol. Bull. 143, 263-292. doi: 10.1037/bul0000089

Buccino, G., Binkofski, F., Fink, G. R., Fadiga, L., Fogassi, L., Gallese, V., et al. (2001). Action observation activates premotor and parietal areas in a somatotopic manner: an fMRI study. Eur. J. Neurosci. 13, 400-404. doi: 10.1046/ j.1460-9568.2001.01385.x

Buccino, G., Colagè, I., Gobbi, N., and Bonaccorso, G. (2016). Grounding meaning in experience: a broad perspective on embodied language. Neurosci. Biobehav. Rev. 69, 69-78. doi: 10.1016/j.neubiorev.2016.07.033

Buccino, G., Marino, B. F., Bulgarelli, C., and Mezzadri, M. (2017). Fluent speakers of a second language process graspable nouns expressed in L2 like in their native language. Front. Psychol. 8:1306. doi: 10.3389/fpsyg.2017.01306

Carey, S., and Bartlett, E. (1978). Acquiring a single new word. Papers Rep. Child Lang. Dev. 15, 17-29.

Chomsky, N. (1965). Aspects of the Theory of Syntax. Cambridge, MA: MIT Press, $16-75$.

Clark, J. M., and Paivio, A. (1991). Dual coding theory and education. Educ. Psychol. Rev. 3, 149-210. doi: 10.1007/BF01320076

Collins, A. M., and Loftus, E. F. (1975). A spreading-activation theory of semantic processing. Psychol. Rev. 82:407. doi: 10.1037/0033-295X.82.6.407

Costa, A., Pannunzi, M., Deco, G., and Pickering, M. J. (2017). Do bilinguals automatically activate their native language when they are not using it? Cogn. Sci. 41, 1629-1644. doi: 10.1111/cogs.12434

De Grauwe, S., Willems, R. M., Rueschemeyer, S. A., Lemhöfer, K., and Schriefers, H. (2014). Embodied language in first-and second-language speakers: neural correlates of processing motor verbs. Neuropsychologia 56, 334-349. doi: 10.1016/j.neuropsychologia.2014.02.003

De Groot, A. M., and Nas, G. L. (1991). Lexical representation of cognates and noncognates in compound bilinguals. J. Mem. Lang. 30, 90-123. doi: 10.1016/ 0749-596X(91)90012-9

Dewaele, J. M. (2004). The emotional force of swearwords and taboo words in the speech of multilinguals. J. Multiling. Multicult. Dev. 25, 204-222. doi: 10.1080/ 01434630408666529

Dijkstra, T., and Van Heuven, W. J. (2002). The architecture of the bilingual word recognition system: from identification to decision. Bilingualism 5, 175-197. doi: $10.1017 /$ S1366728902003012

Dijkstra, T., van Heuven, W. J. B., and Grainger, J. (1998). Simulating crosslanguage competition with the bilingual interactive activation model. Psychol. Belg. 38, 177-196.

Dudschig, C., de la Vega, I., and Kaup, B. (2014). Embodiment and secondlanguage: automatic activation of motor responses during processing spatially associated L2 words and emotion L2 words in a vertical Stroop paradigm. Brain Lang. 132, 14-21. doi: 10.1016/j.bandl.2014.02.002

Eilola, T. M., and Havelka, J. (2011). Behavioural and physiological responses to the emotional and taboo Stroop tasks in native and non-native speakers of English. Int. J. Biling. 15, 353-369. doi: 10.1177/1367006910379263

Ferré, P., Sánchez-Casas, R., and Guasch, M. (2006). Can a horse be a donkey? Semantic and form interference effects in translation recognition in early and late proficient and nonproficient SpanishCatalan bilinguals. Lang. Learn. 56, 571-608. doi: 10.1111/j.1467-9922.2006. 00389.x

Fischer, M. H., and Zwaan, R. A. (2008). Embodied language: a review of the role of the motor system in language comprehension. Quart. J. Exp. Psychol. 61, 825-850. doi: 10.1080/17470210701623605

Foroni, F. (2015). Do we embody second language? Evidence for 'partial'simulation during processing of a second language. Brain Cogn. 99, 8-16. doi: 10.1016/j. bandc.2015.06.006

Gianelli, C., Kühne, K., Mencaraglia, S., and Volta, R. D. (2018). Action processing in the motor system: TMS evidence of shared mechanisms in the visual and linguistic modalities. PsyArXiv [Preprint]. doi: 10.31234/osf.io/gw4v9

Glenberg, A. M., and Kaschak, M. P. (2002). Grounding language in action. Psychon. Bull. Rev. 9, 558-565. doi: 10.3758/BF03196313

Green, D. W. (2003). "The neural basis of the lexicon and the grammar in L2 acquisition," in The Interface Between Syntax and the Lexicon in Second Language Acquisition, eds R. van Hout, A. Hulk, F. Kuiken, and R. Towell (Amsterdam: John Benjamins), 197-208. doi: 10.1075/lald.30. 10gre
Grogan, A., Green, D. W., Ali, N., Crinion, J. T., and Price, C. J. (2009). Structural correlates of semantic and phonemic fluency ability in first and second languages. Cereb. Cortex 19, 2690-2698. doi: 10.1093/cercor/bhp023

Hahne, A. (2001). What's different in second-language processing? Evidence from event-related brain potentials. J. Psychol. Res. 30, 251-266. doi: 10.1023/A: 1010490917575

Harnad, S. (1990). The symbol grounding problem. Physica D 42, 335-346. doi: 10.1016/0167-2789(90)90087-6

Harris, C. L., Ayçiçeği, A., and Gleason, J. B. (2003). Taboo words and reprimands elicit greater autonomic reactivity in a first than in a second language. Appl. Psycholing. 24, 561-578. doi: 10.1017/S0142716403000286

Hauk, O., Johnsrude, I., and Pulvermüller, F. (2004). Somatotopic representation of action words in human motor and premotor cortex. Neuron 41, 301-307. doi: 10.1016/S0896-6273(03)00838-9

Hauk, O., and Pulvermüller, F. (2004). Neurophysiological distinction of action words in the fronto-central cortex. Hum. Brain Mapp. 21, 191-201. doi: 10. 1002/hbm.10157

Kay, J., Lesser, R., and Coltheart, M. (1992). PALPA: Psycholinguistic Assessments of Language Processing in Aphasia. London: Lawrence Erlbaum Associates Ltd.

Kousta, S. T., Vigliocco, G., Vinson, D. P., Andrews, M., and Del Campo, E. (2011). The representation of abstract words: why emotion matters. J. Exp. Psychol. 140, 14. doi: $10.1037 / \mathrm{a} 0021446$

Kroll, J. F., and Borning, L. (1987). Shifting language representations in novice bilinguals: evidence from sentence priming. Paper Presented at the 27th Annual Meeting of the Psychonomic Society, Seattle, WA.

Kroll, J. F., and Stewart, E. (1994). Category interference in translation and picture naming: evidence for asymmetric connections between bilingual memory representations. J. Mem. Lang. 33, 149-174. doi: 10.1016/j.jecp.2008.10.004

Kroll, J. F., Van Hell, J. G., Tokowicz, N., and Green, D. W. (2010). The revised hierarchical model: a critical review and assessment. Bilingualism 13, 373-381. doi: 10.1017/S136672891000009X

Lachmair, M., Dudschig, C., De Filippis, M., de la Vega, I., and Kaup, B. (2011). Root versus roof: automatic activation of location information during word processing. Psychon. Bull. Rev. 18, 1180-1188. doi: 10.3758/s13423-011-0158-x

Lemhöfer, K., and Broersma, M. (2012). Introducing LexTALE: a quick and valid lexical test for advanced learners of English. Behav. Res. Methods 44, 325-343. doi: 10.3758/s13428-011-0146-0

Liu, H., and Cao, F. (2016). L1 and L2 processing in the bilingual brain: a metaanalysis of neuroimaging studies. Brain Lang. 159, 60-73. doi: 10.1016/j.bandl. 2016.05.013

Lotto, A. J., Hickok, G. S., and Holt, L. L. (2009). Reflections on mirror neurons and speech perception. Trends Cogn. Sci. 13, 110-114. doi: 10.1016/j.tics.2008. 11.008

MacWhinney, B. (2005). “A unified model of language acquisition," in Handbook of Bilingualism: Psycholinguistic Approaches, eds J. F. Kroll and A. M. B. de Groot (New York, NY: Oxford University Press), 49-67.

Mahon, B. Z., and Caramazza, A. (2008). A critical look at the embodied cognition hypothesis and a new proposal for grounding conceptual content. J. Physiol. 102, 59-70. doi: 10.1016/j.jphysparis.2008.03.004

Marian, V., Spivey, M., and Hirsch, J. (2003). Shared and separate systems in bilingual language processing: converging evidence from eyetracking and brain imaging. Brain Lang. 86, 70-82. doi: 10.1016/S0093-934X(02)00535-7

Marino, B. F., Sirianni, M., Dalla Volta, R., Magliocco, F., Silipo, F., Quattrone, A., et al. (2014). Viewing photos and reading nouns of natural graspable objects similarly modulate motor responses. Front. Hum. Neurosci. 8:968. doi: 10.3389/ fnhum.2014.00968

McDonald, J. L. (2006). Beyond the critical period: processing-based explanations for poor grammaticality judgment performance by late second language learners. J. Mem. Lang. 55, 381-401. doi: 10.1016/j.jml.2006. 06.006

Mehrpour, M., Motamed, M. R., Aghaei, M., Jalali, N., and Ghoreishi, Z. (2014). Unusual recovery of aphasia in a polyglot Iranian patient after ischemic stroke. Basic Clin. Neurosci. 5:173.

Moseley, R., Kiefer, M., and Pulvermüller, F. (2015). Grounding and embodiment of concepts and meaning. Percept. Emot. Embod. 1:93.

Moseley, R. L., and Pulvermüller, F. (2014). Nouns, verbs, objects, actions, and abstractions: local fMRI activity indexes semantics, not lexical categories. Brain Lang. 132, 28-42. doi: 10.1016/j.bandl.2014.03.001 
Moseley, R. L., and Pulvermüller, F. (2018). What can autism teach us about the role of sensorimotor systems in higher cognition? New clues from studies on language, action semantics, and abstract emotional concept processing. Cortex 100, 149-190. doi: 10.1016/j.cortex.2017.11.019

Newell, A., and Simon, H. A. (1972). Human Problem Solving, Vol. 104. Englewood Cliffs, NJ: Prentice-Hall.

Ojemann, G. A. (1991). Cortical organization of language. J. Neurosci. 11, 22812287. doi: 10.1523/JNEUROSCI.11-08-02281.1991

Parker Jones, Ō, Green, D. W., Grogan, A., Pliatsikas, C., Filippopolitis, K., Ali, N., et al. (2012). Where, when and why brain activation differs for bilinguals and monolinguals during picture naming and reading aloud. Cerebral Cortex 22, 892-902. doi: 10.1093/cercor/bhr161

Perani, D., and Abutalebi, J. (2005). The neural basis of first and second language processing. Curr. Opin. Neurobiol. 15, 202-206. doi: 10.1016/j.conb.2005.03.007

Pillai, J. J., Araque, J. M., Allison, J. D., Sethuraman, S., Loring, D. W., Thiruvaiyaru, D., et al. (2003). Functional MRI study of semantic and phonological language processing in bilingual subjects: preliminary findings. NeuroImage 19, 565-576. doi: 10.1016/S1053-8119(03)00151-4

Ponari, M., Norbury, C. F., and Vigliocco, G. (2017). Acquisition of abstract concepts is influenced by emotional valence. Dev. Sci. 21:e12549. doi: 10.1111/ desc. 12549

Pulvermüller, F. (1999). Words in the brain's language. Behav. Brain Sci. 22, 253-279. doi: 10.1017/S0140525X9900182X

Pulvermüller, F. (2013). How neurons make meaning: brain mechanisms for embodied and abstract-symbolic semantics. Trends Cogn. Sci. 17, 458-470. doi: 10.1016/j.tics.2013.06.004

Pulvermüller, F., and Fadiga, L. (2010). Active perception: sensorimotor circuits as a cortical basis for language. Nat. Rev. Neurosci. 11:351. doi: 10.1038/nrn2811

Pulvermüller, F., Hauk, O., Nikulin, V. V., and Ilmoniemi, R. J. (2005). Functional links between motor and language systems. Eur. J. Neurosci. 21, 793-797. doi: 10.1111/j.1460-9568.2005.03900.x

Rüschemeyer, S. A., Zysset, S., and Friederici, A. D. (2006). Native and nonnative reading of sentences: an fMRI experiment. Neuroimage 31, 354-365. doi: 10.1016/j.neuroimage.2005.11.047

Sakreida, K., Scorolli, C., Menz, M. M., Heim, S., Borghi, A. M., and Binkofski, F. (2013). Are abstract action words embodied? An fMRI investigation at the interface between language and motor cognition. Front. Hum. Neurosci. 7:125. doi: 10.3389/fnhum.2013.00125

Sheikh, N. A., and Titone, D. (2016). The embodiment of emotional words in a second language: an eye-movement study. Cogn. Emot. 30, 488-500. doi: 10.1080/02699931.2015.1018144

Shtyrov, Y., Hauk, O., and Pulvermüller, F. (2004). Distributed neuronal networks for encoding category-specific semantic information: the mismatch negativity to action words. Eur. J. Neurosci. 19, 1083-1092. doi: 10.1111/j.0953-816X.2004. 03126.x

Spalek, K., Hoshino, N., Wu, Y. J., Damian, M., and Thierry, G. (2014). Speaking two languages at once: unconscious native word form access in second language production. Cognition 133, 226-231. doi: 10.1016/j.cognition.2014.06.016

Stroop, J. R. (1935). Studies of interference in serial verbal reactions. J. Exp. Psychol. 18, 643-662. doi: 10.1037/h0054651
Tettamanti, M., Buccino, G., Saccuman, M. C., Gallese, V., Danna, M., Scifo, P., et al. (2005). Listening to action-related sentences activates fronto-parietal motor circuits. J. Cogn. Neurosci. 17, 273-281. doi: 10.1162/0898929053124965

Toni, I., De Lange, F. P., Noordzij, M. L., and Hagoort, P. (2008). Language beyond action. J. Physiol. Paris 102, 71-79. doi: 10.1016/j.jphysparis.2008. 03.005

Ullman, M. T. (2001). The neural basis of lexicon and grammar in first and second language: the declarative/procedural model. Bilingualism 4, 105-122. doi: $10.1017 /$ S1366728901000220

Van Heuven, W. J., Dijkstra, T., and Grainger, J. (1998). Orthographic neighborhood effects in bilingual word recognition. J. Mem. Lang. 39, 458-483. doi: 10.1006/jmla.1998.2584

Vigliocco, G., Norbury, C., and Ponari, M. (2017). How do Young Children Learn Abstract Concepts? Final Public Report. Available at: http://www.nuffieldfoundation.org/sites/default/files/files/Vigliocco\% 2040477\%20-\%20Full\%20public\%20report.pdf

Von Studnitz, R. E., and Green, D. W. (1997). Lexical decision and language switching. Int. J. Biling. 1, 3-24. doi: 10.1177/136700699700100102

Vukovic, N., Feurra, M., Shpektor, A., Myachykov, A., and Shtyrov, Y. (2017). Primary motor cortex functionally contributes to language comprehension: an online rTMS study. Neuropsychologia 96, 222-229. doi: 10.1016/j. neuropsychologia.2017.01.025

Vukovic, N., and Shtyrov, Y. (2014). Cortical motor systems are involved in secondlanguage comprehension: evidence from rapid mu-rhythm desynchronisation. NeuroImage 102, 695-703. doi: 10.1016/j.neuroimage.2014.08.039

Vukovic, N., and Williams, J. N. (2014). Automatic perceptual simulation of first language meanings during second language sentence processing in bilinguals. Acta Psychol. 145, 98-103. doi: 10.1016/j.actpsy.2013.11.002

Werker, J. F., and Tees, R. C. (1999). Influences on infant speech processing: toward a new synthesis. Ann. Rev. Psychol. 50, 509-535. doi: 10.1146/annurev.psych.50. 1.509

Williams, J. N., and Cheung, A. (2011). "Using priming to explore early word learning," in Applying Priming Methods to L2 Learning, Teaching and Research: Insights from Psycholinguistics, eds P. Trofimovich and K. McDonough (Amsterdam: John Benjamins), 73-103.

Zwaan, R. A., and Madden, C. J. (2005). “Embodied sentence comprehension," in Grounding Cognition: The Role of Perception and Action in Memory, Language, and Thought, eds D. Pecher and R. Zwaan (New York, NY: Cambridge University Press), 224-245.

Conflict of Interest Statement: The authors declare that the research was conducted in the absence of any commercial or financial relationships that could be construed as a potential conflict of interest.

Copyright (C) 2019 Kühne and Gianelli. This is an open-access article distributed under the terms of the Creative Commons Attribution License (CC BY). The use, distribution or reproduction in other forums is permitted, provided the original author(s) and the copyright owner(s) are credited and that the original publication in this journal is cited, in accordance with accepted academic practice. No use, distribution or reproduction is permitted which does not comply with these terms. 